DOI: https://doi.org/10.47405/mjssh.v6i4.768

\begin{tabular}{|c|c|}
\hline 4.581 & Malaysian Journal of Social Sciences and Humanities (MJSSH) \\
\hline $\begin{array}{l}\text { Malaysian Journal of } \\
\text { Social cciences and }\end{array}$ & Volume 6, Issue 4, April 2021 \\
\hline (MJ-SSH) & e-ISSN : 2504-8562 \\
\hline & $\begin{array}{l}\text { Journal home page: } \\
\text { www.msocialsciences.com }\end{array}$ \\
\hline
\end{tabular}

\title{
Spatial-Temporal Distribution of Malaria Risk and Its Association With El Niño Southern Oscillation (ENSO)
}

\author{
Ricky Anak Kemarau' ${ }^{1}$, Oliver Valentine Eboy ${ }^{\mathbf{1}}$ \\ ${ }^{1}$ Geography Program, Faculty of Social Science and Humanities, Universiti Malaysia Sabah (UMS) \\ Correspondence: Ricky Anak Kemarau (ricky.geo2005@gmail.com)
}

\begin{abstract}
Sarawak recorded the second-highest number of cases since 2013 until 2017 after Sabah. Sarawak is the largest state in Malaysia and needs to provide spatial information, especially to the ministry of health. The objective of this study was to examine the impact of El Niño-Southern Oscillation (ENSO) on the distribution of malaria risk maps. To achieve the objectives of this study requires Oceanic Niño Index (ONI) data, Visible Infrared Imaging Radiometer Suite (VIIRS), daily temperature, and secondary data on the number of malaria cases in Sarawak. The results of the study clearly show that the occurrence of La Niña and El Niño affects the total distribution of Malaria risk maps. The number of malaria cases is also related to the ONI value. The lower the ONI value causes the malaria case value to decrease. The results of this study suggest that most of the hot spots in the forest, forest fringe, and inland areas of Sarawak. This clearly shows the lack of knowledge and knowledge causing the rural population to be prone to malaria. The Ministry of Health needs to focus on the interior in disseminating teachings and knowledge in dealing with malaria mosquitoes.
\end{abstract}

Keywords: spatial-temporal, ENSO, malaria risk map, remote sensing

\section{Introduction}

By 2020, the World Health Organization (WHO) has identified that Malaysia is on the list of 21 potential countries where malaria can be epidemic to humans. Although malaria cases are reported to be declining, the need to increase measures to control and eradicate malaria is a major problem, especially in rural areas where the population lacks knowledge or education to deal with malaria, especially in Sarawak and Sabah compared to Peninsular Malaysia (Hussin et. al., 2020). Hussien et al., (2020) stated that the states of Sabah and Sarawak recorded the highest accumulated cases from 2013 to 2017 of 7150 in Sabah and 5684 in Sarawak representing 77.7\% of all cases in Malaysia. This explains why the researcher chose the state of Sarawak as the study area. Furthermore, Hussin et al. (2020) strongly recommended that a complete geographical distribution map is very important. Besides, those responsible should understand the geographical distribution of Malaria is another key point to identify high-risk infection areas and plan appropriate control strategies and surveillance systems. It is also important to project areas where malaria transmission is most likely to occur even if human malaria has been controlled. The use of satellite technology that studies weather and climate is very important in the use of climate indicators to predict the risk of malaria. In African countries, the use of remote sensing technology in predicting malaria is widely practiced (Thomson et al, 2001; Teklehaimanot et al., 2004), but for other malaria-endemic areas, such technology is underdeveloped. For example, similar studies are rare in Asia and rarer in Malaysia (Husin et al., 2020). A large 
number of literature reviews as described below use predict malaria risk using GIS and remote sensing using weather and climate factor parameters especially rain and temperature. However, the study did not examine the effects of ENSO on malaria. In this study, researchers tried to predict the risk of malaria map during ENSO occurrence using VCI.

\section{Literature review}

The latest study and similar to this study are Hasyim et al., (2018) who conducted a study in South Sumatra Province, Indonesia. Their study of the spatial association between malaria occurrence and environmental risk factors used GIS Analysis ordinary least square (OLS) and geographically weighted regression (GWR) in producing six potential ecological predictors of malaria cases map. Their study found that independent variables such as altitude, distance from forest, and rainfall play a role in increasing malaria cases. The amount of rainfall plays an important role in the spread of malaria. The results of this study were also found to be similar to the study conducted by Alemu et al., (2010) in Jimma Town, South West Ethiopia. Excessive rainfall and temperatures ranging from 25-27 degrees Celsius will increase the life span of malaria mosquitoes and increase the distribution of malaria mosquito breeding sites (Yamana et al., 2013; Abiodun et al., 2016; Weaver et al., 2014). At 28 degrees Celsius and lack of moisture will shorten the life span of mosquitoes (Yamana et al., 2013). The first study in Asia using remote sensing technology was Adimi et al., (2010) who conducted a study on making malaria risk predictions in Afghanistan. Their study predicted malaria risk from 2004-2007 using Moderate Resolution Imaging Spectroradiometer (MODIS) and Tropical Rainfall Measuring Mission (TRMM). MODIS data provides temperature data, vegetation index, and TRMM rainfall data. Their study uses regression technique in building malaria cases model based on environmental predictors. The results of their study found that vegetation index through Normalized Difference Vegetation Index (NDVI) is the strongest predictor in the spread of malaria. Their study used a linear regression model in predicting the spread of malaria. Mushinzimana et al., (2006) studied landscape determinants of anopheline mosquito larva habitats and used remote sensing technology in identifying their habitats in western Kenya Highlands. Their study used aerial photos, IKONOS and Landsat Thematic Mapper 7. The study compared the effectiveness of the three data in identifying mosquito habitats. Based on their results, it was found that IKONOS images were able to identify 40.6\% compared to aerial photos and 0 for Landsat. Midekisa et al., (2012) first study using seasonal autoregressive integrated moving average (SARIMA) models in measuring the relationship between malaria cases and remote sensing environmental variables namely rainfall. Land surface temperature and vegetation indices such as NDVI and EVI and lastly evapotranspiration. Their study found that these malaria cases were positively related to land surface temperature, rainfall, EVI, and transpiration. Dhimal et al., (2014) studied the spatial-temporal distribution of malaria and the relationship between malaria and climate factors and vector control interventions in Nepal. Their study found that malaria micro-stratification, mosquito repellents should be prescribed for those living in the forest, forest fringe, and foothill. Based on previous studies it was found that vegetation indices such as NDVI, rainfall factor, and temperature play an important role in the spread of malaria. However, there have been no attempts to study the relationship between ENSO and the spread of malaria using remote sensing. In addition to testing the VIIRS sensor in studying the spread of malaria is still lacking. This study also uses the Vegetation Condition Index (VCI) which was first tested in studying its relationship with malaria.

\section{Method and study area}

VIIRS satellites were used in this study. Data used from 2013 to 2020. However, this study only focuses on two ENSO incidents in La Niña in late 2017 and early 2018 and El Niño 2015/2016. Data has been downloaded from the National Center for Applications and Research, National Environmental Satellite Data and Information Services, NOAA, and its URL is https://www.star.nesdis.noaa.gov/smcd/emb/vci/VH/index .php. Apart from VIIRS data, this study also uses Oceanic Niño Index (ONI) data, daily and monthly temperatures from the Malaysian 
meteorological department (MMD). In-depth information on ONI data, malaria cases, and temperature will be discussed in the next chapter.

\section{Study Area}

The study area is the state of Sarawak. According to Zulfaqar et al., (2017), the temperature in the study area is hot throughout the year with an average daily temperature between 23 degrees Celsius in the early morning to 32 degrees Celsius during the day. Sarawak's climate is influenced by Madden Julian Oscillation, El Niño Southern Oscillation (ENSO), Indian Ocean Dipole (IOD), and Monsoon season (Dindang et al., 2013; Yik et al., 2015). The occurrence of the ENSO phenomenon plays an important role in shaping the daily weather in the study area. In 1997/1998 and 2015/2016 saw a prolonged drought and forest fires. Meanwhile, 2009 saw heavy rains and caused major floods in lowland areas in Sarawak. These extreme weather changes have aroused many researchers' interest in conducting analytical studies on meteorological data and remote meteorological remote sensing. Going back to this study, the question that arises is whether the occurrence of ENSO affects the risk of Malaria.

Figure 1: Study Areas

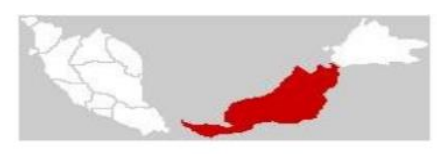

\section{SARAWAK}

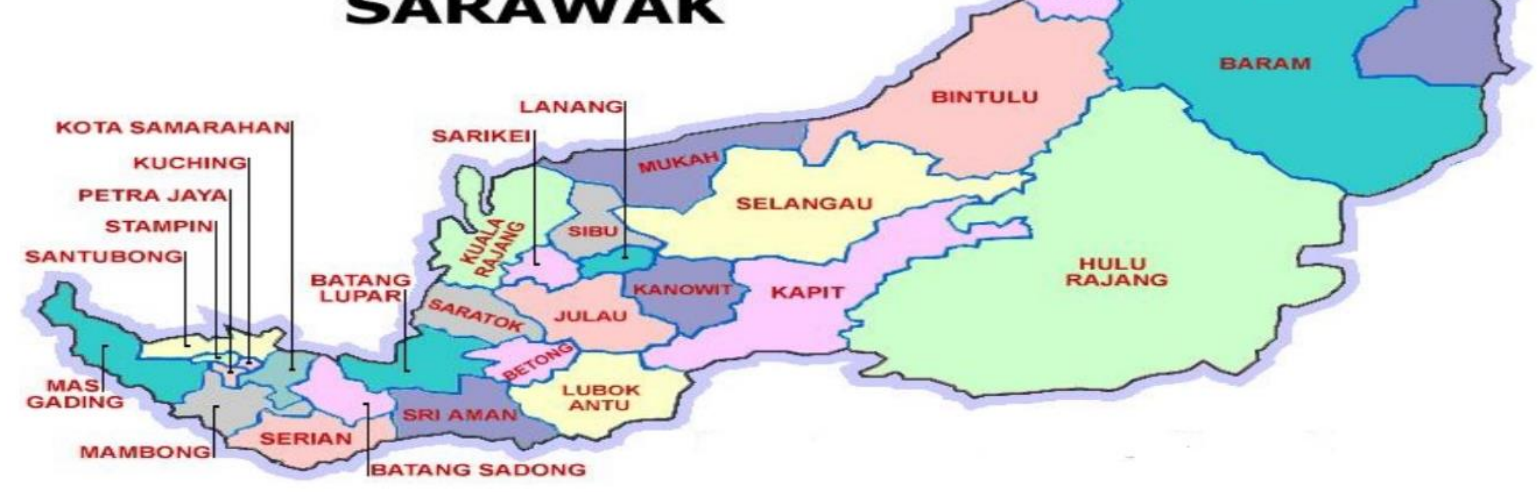

\section{Vegetation Index}

The Vegetation Condition Index (VCI) is the best parameter for plants to respond to total rainfall. Refers to VCI capable of capturing water-related stress.

$$
\mathrm{VCI}=100 \times(\mathrm{NDVI}-\mathrm{NDVImin}) /(\mathrm{NDVImax}-\mathrm{NDVImin})
$$

Where NDVImax and NDVImin are the maximum and minimum values of NDVI. Kogan (1990) stated that VCI is more sensitive to the value of dynamic rainfall than NDVI.

\section{Oceanic Niño Indeks (ONI)}

The ONI is well established to identify events of El Niño and La Niña (Rojas et al., 2014; NOAA, 2020). The ONI index shows the development and intensity of El Niño or La Niña events in the Pacific Ocean. ONI is a three-month Sea Temperature (SST) anomaly in Niño region $3.45^{\circ} \mathrm{N}-5^{\circ} \mathrm{S}$, $120^{\circ}-170^{\circ} \mathrm{W}$ ). The occurrence of El Niño is defined when the average value of three months at or above $+0.5^{\circ} \mathrm{C}$ anomaly, while the event of La Niña is defined as or under climate Anomaly (NOAA, 2020) $-0.5^{\circ} \mathrm{C}$ (NOAA Forecast Center, 2019). 
Table 1: Classification of ENSO Strength Events.

\begin{tabular}{cccc}
\hline Value ONI & El Niño Classification & Value ONI & La Niña Classification \\
\hline $0.5-0.9$ & Weak & $(-) 0.5-(-) 0.9$ & Weak \\
$1.0-1.4$ & Medium & $(-) 1.0-(-) 1.4$ & Medium \\
$1.5-1.9$ & Strong & $(-) 1.5-(-) 1.9$ & Strong \\
$\geq 2.0$ & Very Strong & $\geq(-) 2.0$ & Very Strong \\
\hline
\end{tabular}

ENSO value grade is classified into 5 classes as mentioned in table 1.

\section{Average Daily Temperature, Maximum Temperature (Max), And Minimum Temperature (Min)}

Daily average temperature data were collected from MMD. Data were collected at Kuching Airport station with latitude 01 degrees 29 'North and longitude 110 degrees 20' East and high above M.S.L 21.7 meters. Data in degrees Celsius. Data used from 2010 to 2019. The monthly mean temperature is calculated from the daily temperature, the maximum value for a month, and the minimum value for a month as shown in table 1 mentioned below.

\section{Malaria Case}

Secondary data on confirmed malaria cases are from Hussin et al., (2020) where they obtained information on malaria cases from the Ministry of Health Malaysia between January 2013 to December 2017. The Malaysian Prevention and Control of Infectious Diseases Act 1988 state that all laboratory-confirmed cases of malaria must be notified to the nearest District Health Office within 7 days of confirmed diagnosis. The State Health Department compiles all data for the whole state before sending the data to the central national level.

\section{Results and discussion}

Figure 2: The pattern of ONI values from 2000 to 2019

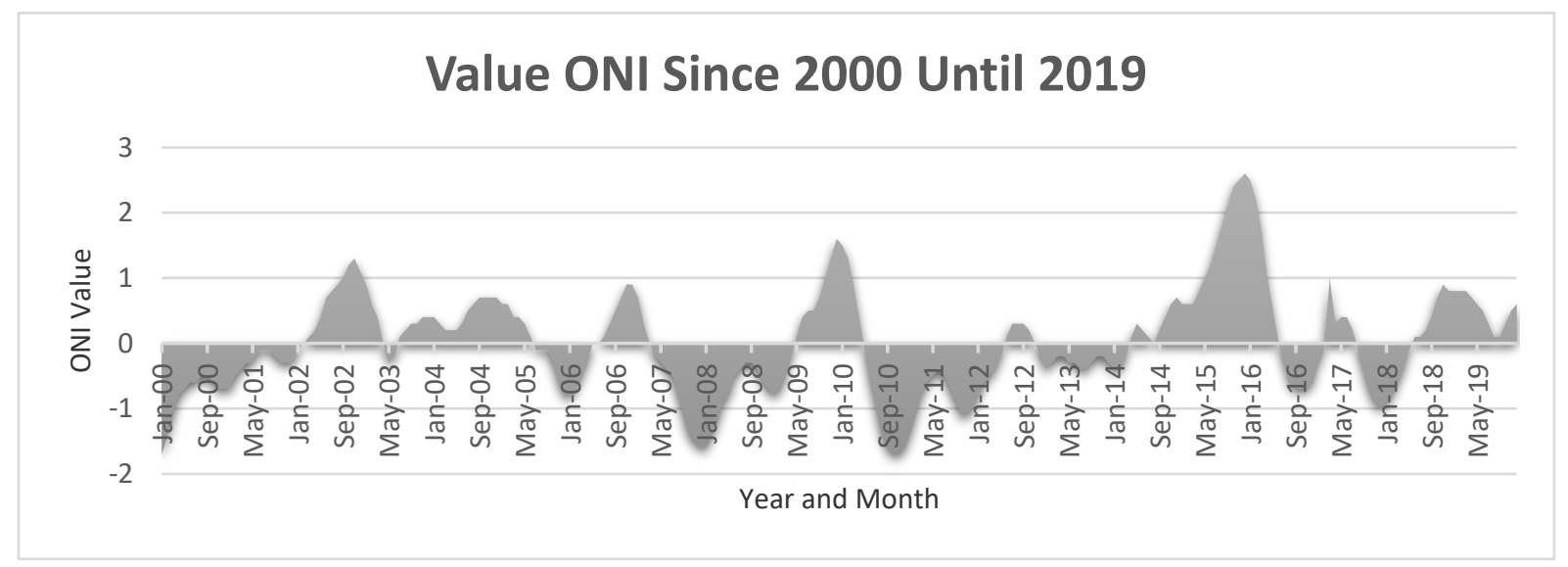

Referring to the graph above shows the pattern of ONI values from 2000 to 2019. Based on NOAA (2020) statement, El Niño representing ONI values starts from positive 0.5 and above and for La Niña its value starts from negative 0.5 and below. During the year 2000 to 2019, there were 6 La Niña incidents namely 2000, 2006, 2007 until January 2009, 2010/2012 and in July 2016 and end year 2017 until January 2018. While the El Niño incidents were in April 2002 until January 2003, October 2009, and 2015 / 2016. El Niño in 2015/2016 is the worst El Niño ever recorded in history that seems to have happened in 1997/1998. This is the same as stated by Tang et al., (2019) and Mou et al., (2020). 


\section{Temperature and ONI Value Patterns from 2010 to 2019}

Figure 3: The value of ONI and meteorological MMD for the month from 2011 to 2019

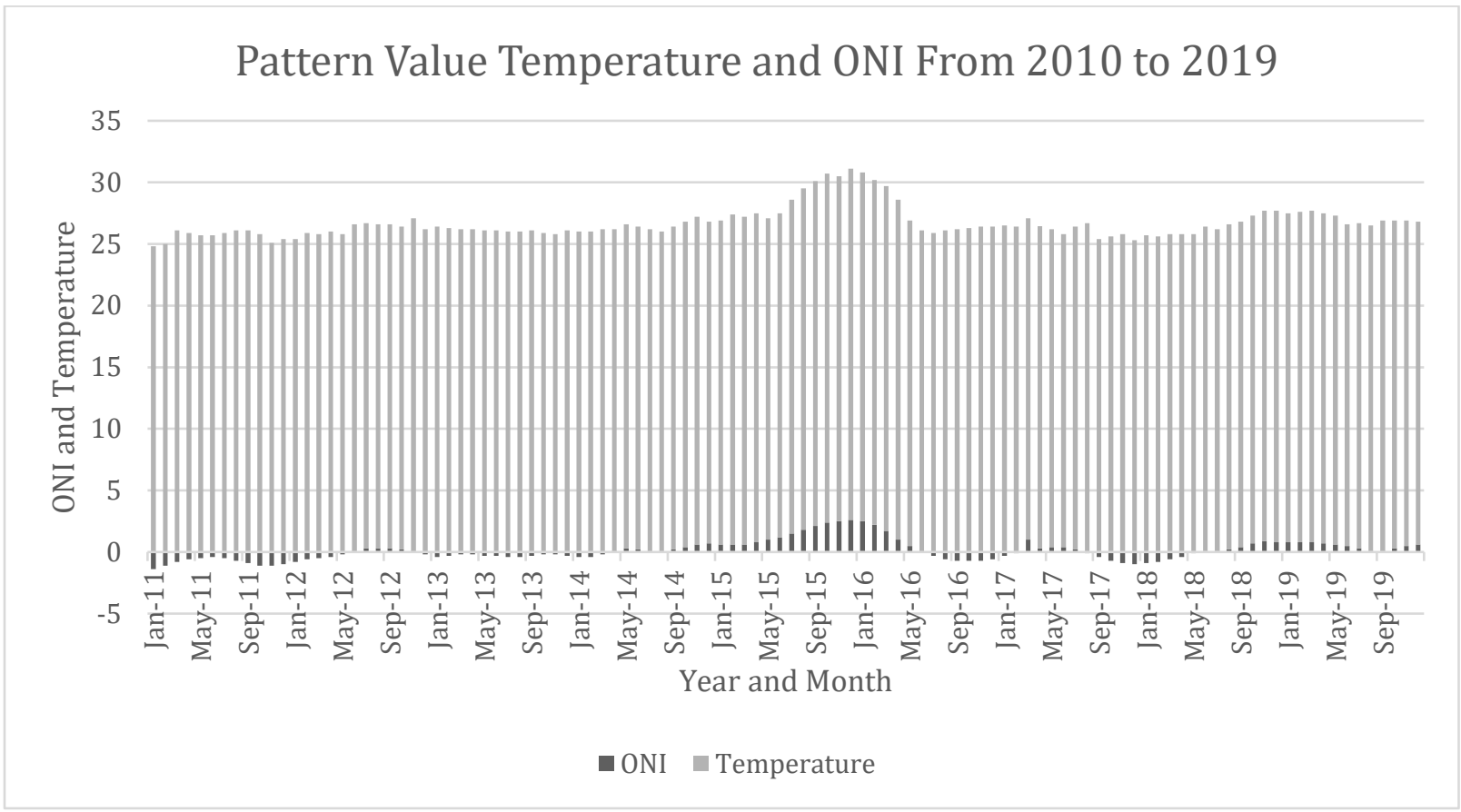

Graph 3 above shows that there is a positive relationship between ONI and monthly temperature. From May 1988 to May 1989 showed that the ONI value -1 to -1.8 equals 24.8 to $24^{\circ} \mathrm{C}$. The negative value of the ONI represented La Niña in the year included from June 1998, 2007, and 2010. In contrast, 1997 from June 1997 to April 1998 showed ONI values at 0.8 to 2.4 in November 1997 and December 1997. The values have increased the temperature in the name of the temperature value is 26.4 to $27.9^{\circ}$ C. This phenomenon is the same from the end of 2015 to March 2016. El Niño can also have occurred in 1991,1 997 to 1998 and 2015 to 2016 (Tang et al., 2019, Tan et al., 2019).

Figure 4: The direct correlation between ONI and meteorological temperature for three months based on ONI monthly formula

Correlation Between Temperature and ONI.

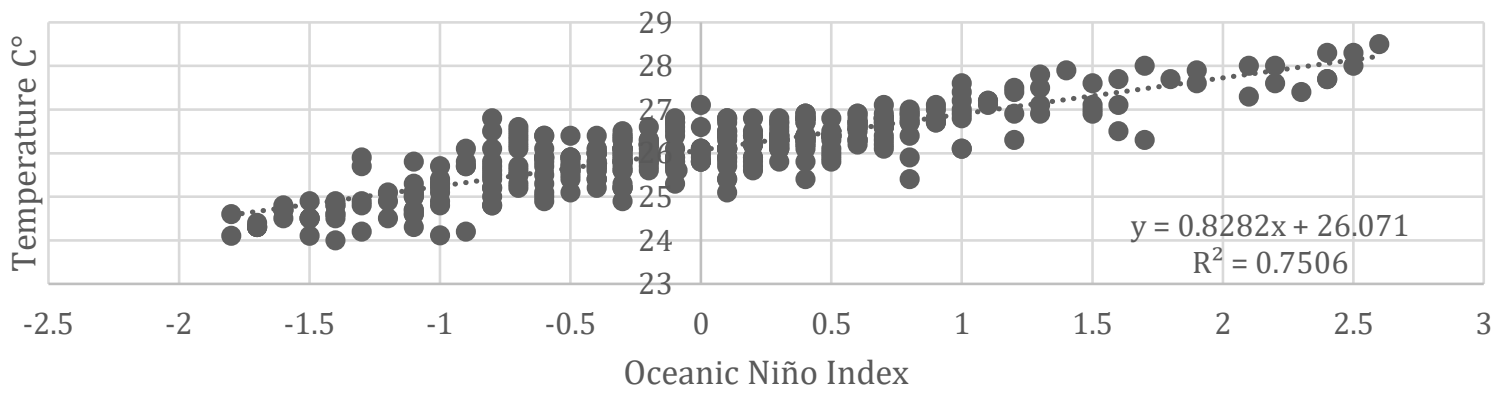

This correlation involves 385 temperatures from MMD from 1988 to 2019. The results show a strong positive correlation between the two variables namely ONI which represents ENSO with the temperature from MMD with a value of $0.75 \mathrm{R}$. 
Figure 5: The ONI and VCI values pattern during the 2015/2016 El Niño incident

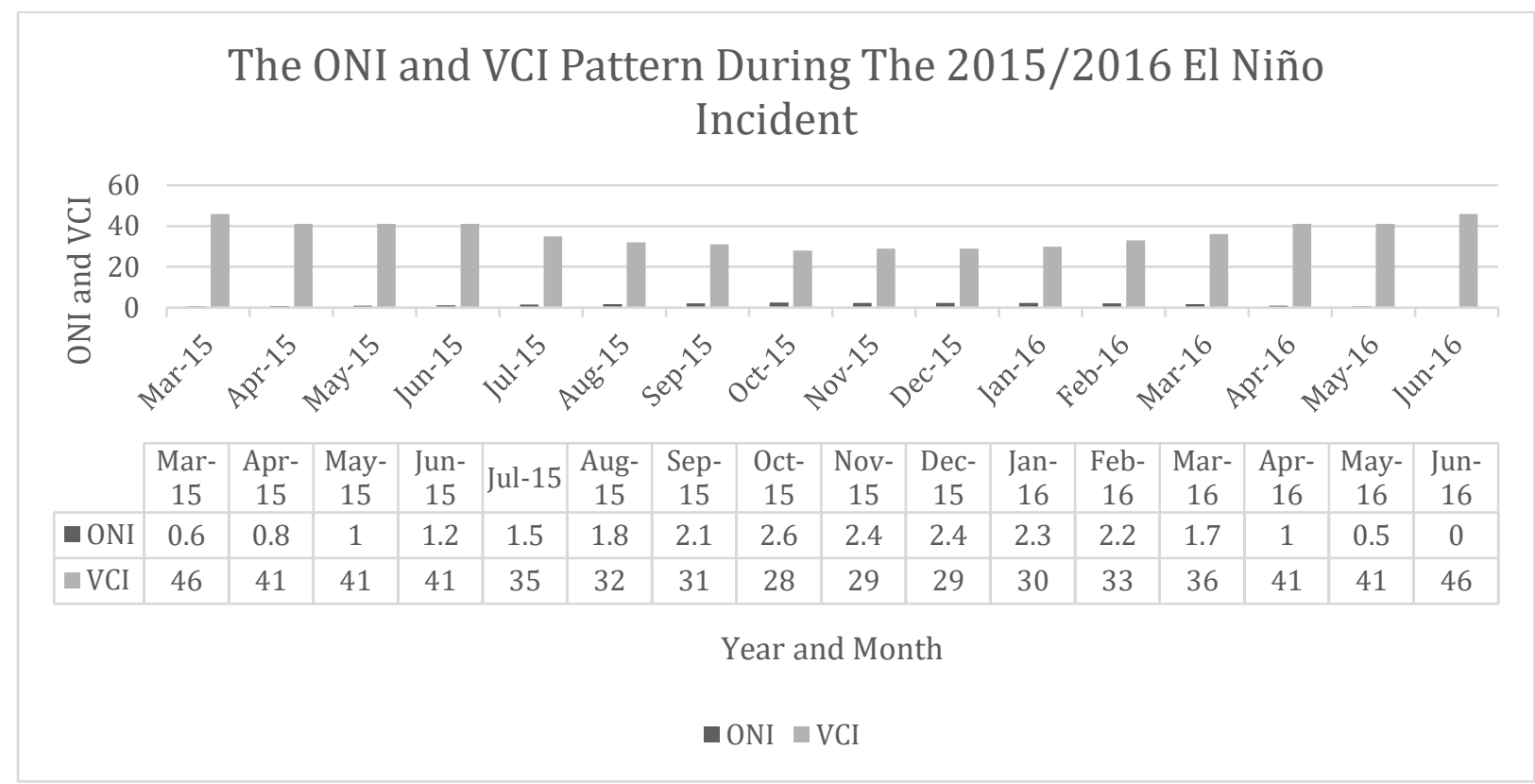

Figure 5 showing ONI and VCI values during El Niño 2015/2016. Based on the table above shows that the ONI value increases will cause the VHI value to decrease as described below. If the ONI Value is 1.2 then the VCI value is 41 and if the ONI value decreases to 2.1 then the VHI value is 31 . An increase in the ONI value means an increase in temperature or an increase in the degree of El Niño strength. For El Niño 2015/2016 events are found to start in March 2015 and increase until October 2015 and decrease in November 2016. The strength of El Niño depends on the value of ONI. The effect of El Niño on plant health depends on the value of ONI. The diagram below will explain more about the effect of ENSO on plant health in the form of space.

Figure 6: The pattern ONI and VHI During La Niña Incident 2017/2018

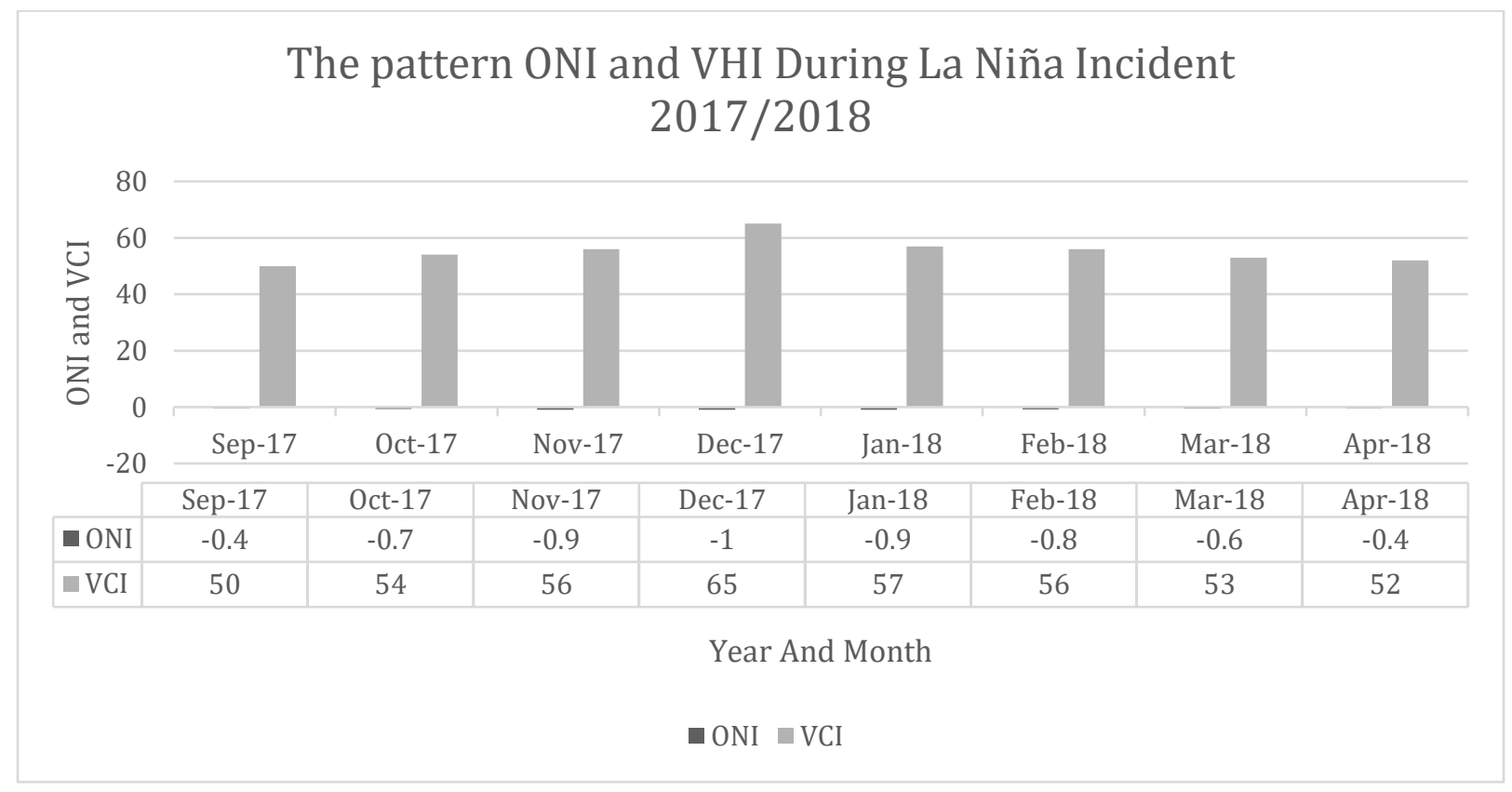

Figure 6 shows the pattern of the ONI and VHI values during the La Niña incident in late 2017 and early 2018. Based on the diagram above shows the decreased ONI value will cause an increase in VHI value. For example in October 2017 where the ONI value is negative 0.7 then the VHI value is 54. 
Whereas if the ONI value is negative 1 eat the VHI value is 65 . Based on the evidence from NOAA (2020) classify if the negative ONI value 0.5 and below is classified as La Niña. This explains why the La Niña incident also had a good effect on VHI. A more in-depth description of La Niña's impact on VHI will be explained through the VHI map below. ONI values have a significant effect on the distribution of VHI values.

Figure 7: Number of malaria cases and deaths according to a year from 2013 to 2017 At Sarawak

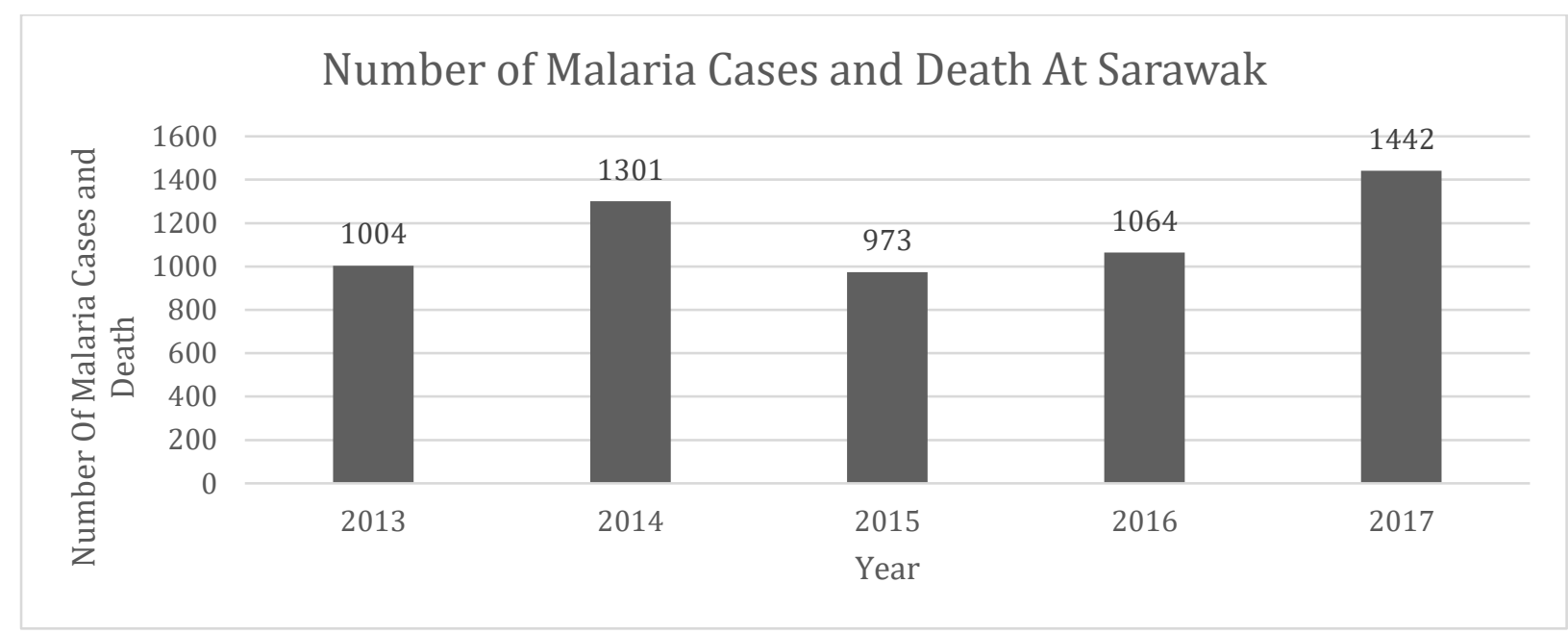

Figure 8 shows malaria cases and deaths due to malaria confirmed by the Ministry of Health Malaysia for 2013 to 2017. In 2013 malaria cases were recorded as 1004 increased to 1301 in 2014. But in 2015 malaria cases were found to decrease to 973 cases and increase slightly in 1064. In 2017 there was a sharp increase to 1442 in 2017. Cooper et al., (2017) stated that the decline in malaria cases in 2015 was due to the El Niño incident that hit Sarawak in that year. The El Niño incident led to changing rainfall and weather patterns which impact the vector bionomics (Copper et al., 2017). Things can be explained in more detail on the malaria risk map in the next chapter. Dhimal et al., (2014) reported that the effects of rainfall on malaria are complex. In some areas, the effects of heavy rainfall are providing breeding grounds and encouraging mosquito population growth. However, heavy rainfall can cause the breeding grounds to disappear and thus decrease the abundance of mosquitoes. For this study, researchers used the Vegetation Condition Index (VCI) because of the response to the amount of rainfall. VCI values range from 0 to 100 . Classification of VCI values in classifying water content conditions and malaria risk as shown in the table below. Suwito et al., (2010) found that temperature plays an important role in determining the intensity of mosquito volume. The density of mosquitoes in the monsoon season where temperatures range from 26-26.5 degrees Celsius is the peak time of mosquito numbers. The number of malaria mosquitoes began to decline at 27 degrees Celsius. He also stated that air humidity plays an important role in contributing to the density of mosquitoes, especially in December in Indonesia. Their study also found that low humidity will shorten the life of mosquitoes and high humidity prolong the life of mosquitoes

Table 1: Classification of Value VCI, Water Content, and Malaria Risk.

\begin{tabular}{ccc}
\hline Value VCI & Classification Water Content & Classification Malaria Risk \\
\hline $75-100$ & Very High-Water Content & Very High \\
$50-75$ & Normal Water Content & Normal High \\
$25-50$ & Moderate Low Water Content & Moderate Low \\
$0-25$ & Very Low Water Content & Very Low \\
\hline
\end{tabular}

The table above shows the classification of water content and malaria risk using VCI. If the VCI value is 75 to 100 then it is classified as very high-water content and very high risk of malaria, 50 to 75 is normal malaria risk and moderate water content. While 25 to 50 means moderate low water content and risk of malaria and the last value of 0 to 25 means very low risk of malaria and water content. 

DOI: https://doi.org/10.47405/mjssh.v6i4.768

Figure 8: Map of malaria risk distribution on the left and map on the right of malaria risk map in average units during El Niño events in 2015/2016
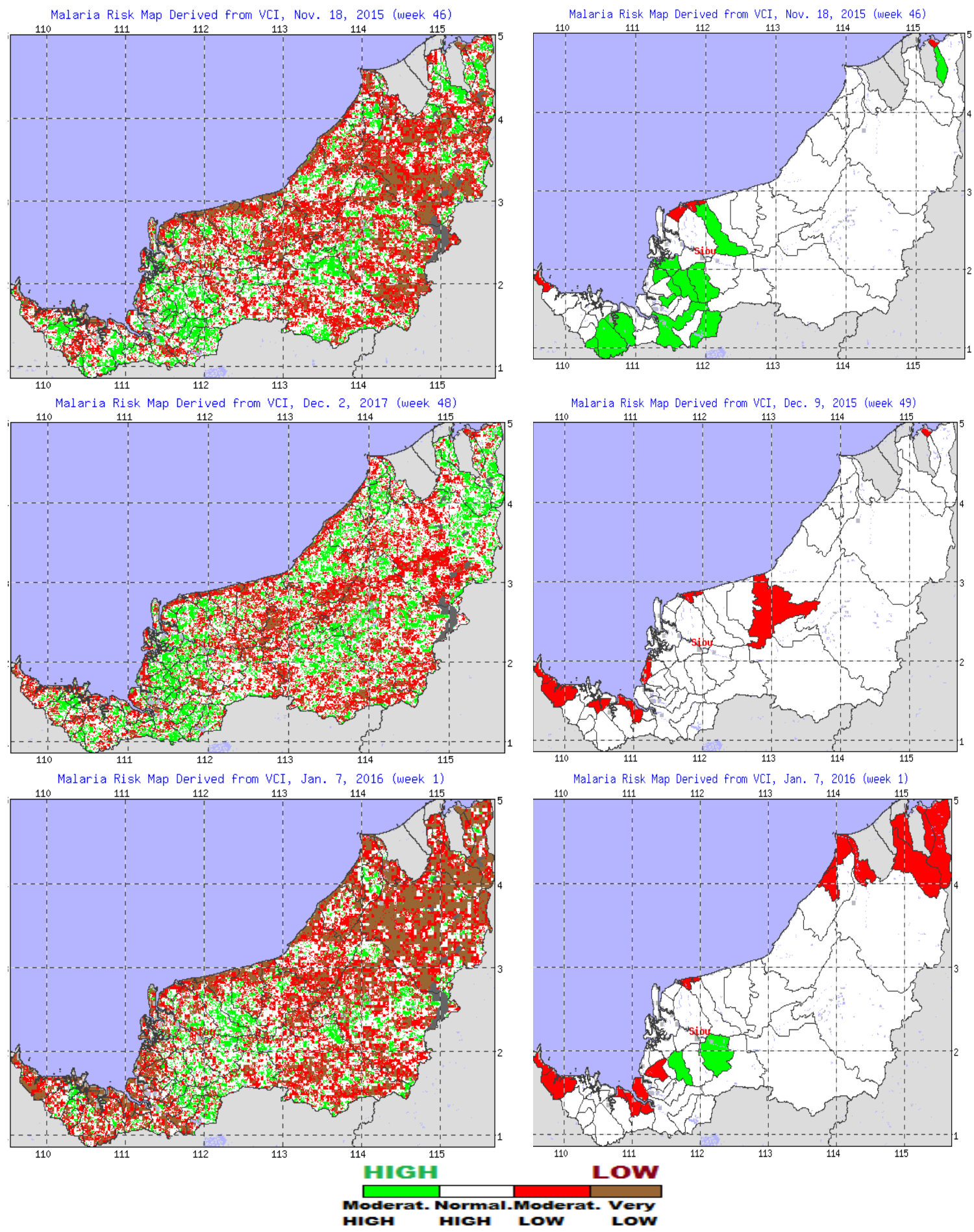

It can be seen that the malaria risk map in November 2015 where the ONI value is 2.1 found the Mukah, Sibu, Lubuk Antu, Serian, and Sarikei districts have a green status which is high risk and the rest areas have normal status. However, the malaria risk distribution in December 2015 and January 2016 where the ONI values of 2.4 and 2.5 showed a change in the mosquito risk distribution where in November the area had normal status and low-risk malaria only. This explains the distribution of spatial malaria risk changes based on ONI rates. El Niño events lower the risk of malaria. 

DOI: https://doi.org/10.47405/mjssh.v6i4.768

Figure 9: Map of malaria risk distribution on the left and map on the right of malaria risk map in average units during El Niño events in 2017/2018
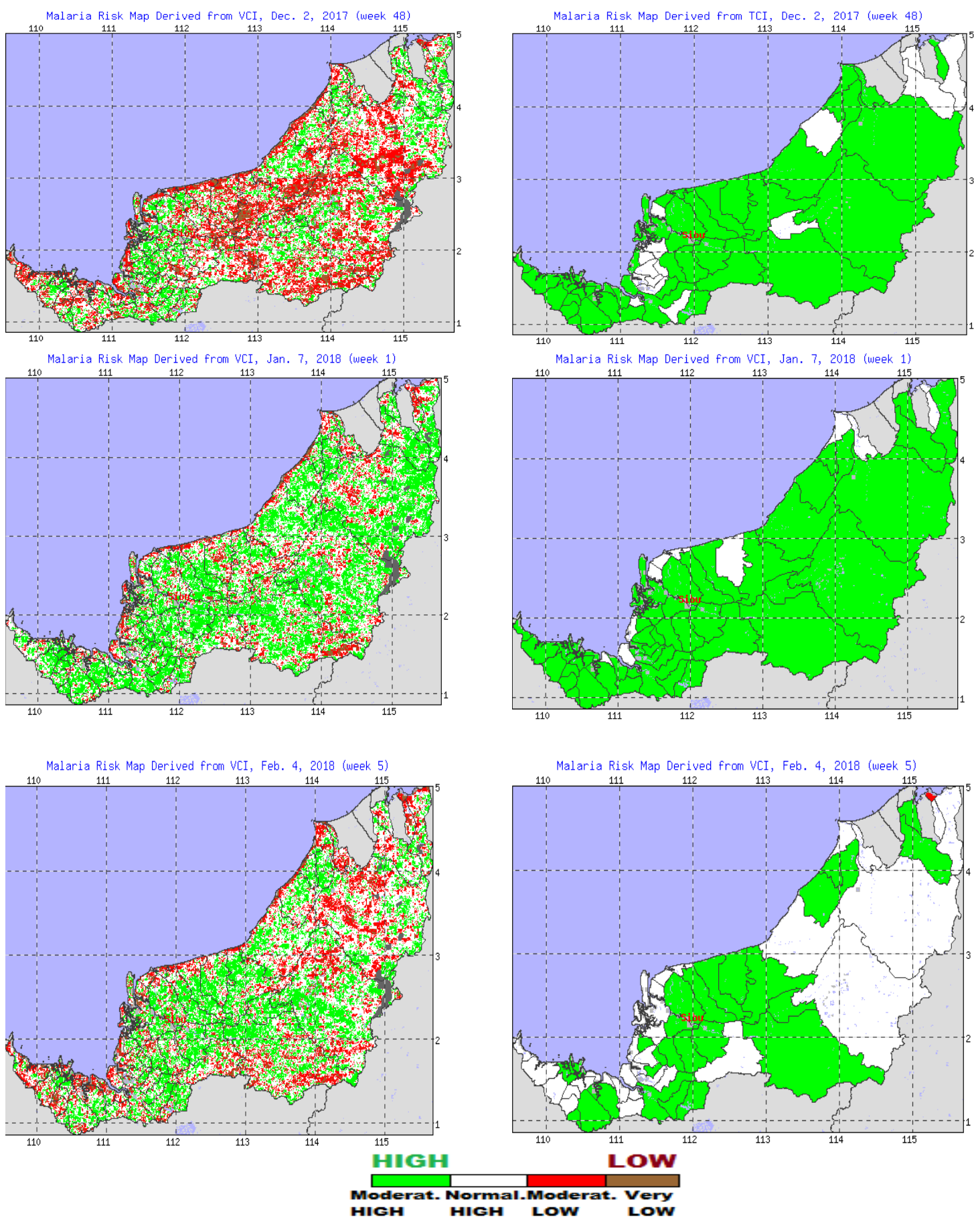

Based on figure 9 , it is found that the distribution of moderately high-risk malaria risk especially in December 2017 and January 2018 where the value of ONI is ONI is negative 0.9 and 1 almost all of Sarawak except 11 districts such as Sibu, Sarikei, Balingian, Belawai and Tanjung Manis. Based on figures 9 and 8 clearly shows a significant difference where during the La Niña incident that is figure 9 many green areas that have a high risk of malaria compared to the La Niña incident. This proves that VCI values play an important role in predicting malaria risk. Besides, it can be observed that the malaria hot spot risk area of most inland areas consists of forest areas. 
Figure 10 shows the difference in VCI values during the events of La Niña 2017/2018 and El Niño $2015 / 2016$

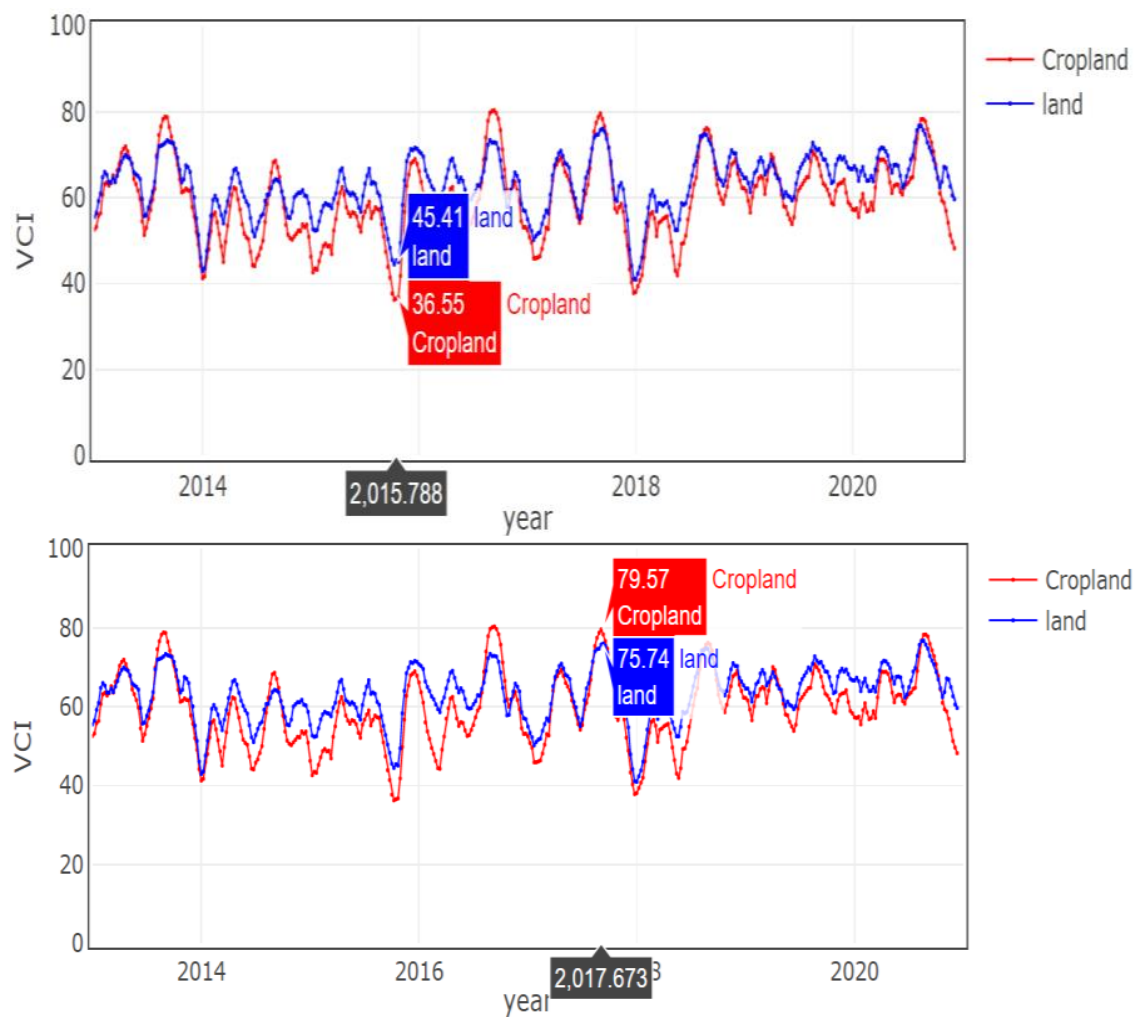

The diagram above clearly shows a lower VCI value during the El Niño incident which is 45.41 for land plants and 36.55 for cropland due to lack of water content due to lack of rainfall compared to during the La Niña incident which is 79.57 and 75.74 during the La Niña incident. VCI values are positively related to the total risk of malaria as well as the number of mosquitoes. In addition to previous studies also found that the humid conditions during the occurrence of La Niña will prolong the life of malaria mosquitoes compared to during the occurrence of El Niño (Hasyim et al., 2018).

\section{Conclusion}

This study succeeded in achieving the objective of the study which is to study the impact of ENSO on malaria risk distribution. This study clearly shows the occurrence of La Niña and El Niño affect the distribution of malaria risk in Sarawak. The occurrence of La Niña where the ONI value is low which causes the amount of rainfall to be more than usual causes the distribution of mosquito disease risk to be higher than during El Niño. Through the provision of information in this column, the health sector knows where the area needs to be focused in channeling aid, awareness campaigns, and knowledge to the locals.

\section{Acknowledgment}

Thank you to NOAA and Malaysia Meteorological Department for provides data for this study.

\section{References}

Alemu A, Abebe G, Tsegaye W, Golassa L. (2011) Climatic variables and malaria transmission dynamics in Jimma town, South West Ethiopia. Parasit Vectors, 4, 30. 
Abiodun GJ, Maharaj R, Witbooi P, Okosun KO. (2016). Modeling the influence of temperature and rainfall on the population dynamics of Anopheles arabiensis. Malar J., 15, 364.

Dhimal. M, Robert B O'Hara, Ramchandra Karki, Garib D Thakur, Ulrich Kuch and Bodo Ahrens. (2014). Spatio-temporal distribution of malaria and its association with climatic factors and vector-control interventions in two high-risk districts of Nepal. Malaria Journal, 13, 457 http://www.malariajournal.com/content/13/1/457

H. Hasyim, Af Nursafngi, Ubydul Haque, Doreen Montag, David A. Groneberg, Meghnath Dhimal, Ulrich Kuch and Ruth Müller. (2018) Spatial modeling of malaria cases associated with environmental factors in South Sumatra, Indonesia. Malaria Journal. https://doi.org/10.1186/s12936-018-2230-8

Hussin N, Yvonne Ai-Lian Lim, Pik Pin Goh, Timothy William, Jenarun Jeep, and Rose Nani Mudin (2020). Updates on malaria incidence and profile in Malaysia from 2013 to 2017. Malaria Journal, 19, 55 https://doi.org/10.1186/s12936-020-3135-X

Midekisa. A Gabriel Senay, Geoffrey M Henebry, Paulos Semuniguse, and Michael C Wimberly (2012). Remote sensing-based time series models for malaria early warning in the highlands of Ethiopia. Malaria Journal, 11, $165 \mathrm{http}: / / \mathrm{www} . m a l a r i a j o u r n a l . c o m / c o n t e n t / 11 / 1 / 165$

Mushinzimana E. Stephen Munga, Noboru Minakawa, Li Li, Chen-chieh Feng, Ling Bian, Uriel Kitron, Cindy Schmidt, Louisa Beck, Guofa Zhou, Andrew K Githeko and Guiyun Yan (2006). Landscape determinants and remote sensing of anopheline mosquito larval habitats in the western Kenya highlands. Malaria Journal2006, 5, 13 doi:10.1186/1475-2875-5-13 http://www.malariajournal.com/content/5/1/13

NOAA 2020. National Centers for Environmental Information, State of The Climate: Global Climate Report for Annual 2019. Available at Https://Www.Ncdc.Noaa.Gov/Sotc/Global/201913. (Accessed On 16 March 2020).

Rogers DJ, Randolph SE, Snow RW, Hay SI (2002). Satellite imagery in the study and forecast of malaria. Nature, 415, 710-715.

Tangang, F., Juneng, L., Salimun, E., Sei, K. \& Loh, J. (2012). Climate Change and Variability Over Malaysia: Gaps in Science and Research Information. Sains Malaysiana, 41, 1355-1366.

Teklehaimanot HD, Lipsitch M, Teklehaimanot A, Schwartz J (2004). Weather-based prediction of Plasmodium falciparum malaria in epidemic-prone regions of Ethiopia. Patterns of lagged weather effects reflect biological mechanisms. Malar J, 3(12).

Thomson MC, Connor SJ (2001). The development of malaria early warning systems for Africa. Trends Parasitol, 17(13), 438-445.

Thomson MC, Doblas-Reyes FJ, Hagedorn R, Connor SJ, Phindela T, Morse AP, Palmer TM (2006). Malaria early warnings based on seasonal climate from multi-model ensembles. Nature, 14 , 576-579.

Suwito, Upik. K. Hadi, Sigit Singgah and Sukowati S. (2010). Hubungan Iklim, Kepadatan Nyamuk Anopheles dan Kejadian Penyakit Malaria. J. Entomol. Indo., 1, 42-53

Yamana TK, Eltahir EA. (2003). Incorporating the effects of humidity in a mechanistic model of Anopheles gambiae mosquito population dynamics in the Sahel region of Africa. Parasit Vectors, 6, 235.

Weaver HJ. (2014). Climate change and human parasitic disease. In: Climate change and global health. CABI Nosworthy Way Wallingford UK: (CAB International; 2014:95. Retrieved from https://www.cabi.org/cabebooks/ ebook/20143328432.

Zulfiqar Sa'adi, Shamsuddin Shahid, Tarmizi Ismail, Eun-Sung Chung, And Xiao-Jun Wang (2017). Distributional Changes in Rainfall and River Flow in Sarawak, Malaysia. Asia-Pac. J. Atmos. Sci., 53(4), 489-500. 